\title{
Environmental and anthropogenic influences of movement and foraging in a critically endangered lemur species, Propithecus tattersalli: implications for habitat conservation planning
}

Meredith A Semel ( $\square$ merak91@vt.edu )

Virginia Tech https://orcid.org/0000-0003-4317-8602

Heather N Abernathy

Virginia Tech: Virginia Polytechnic Institute and State University

Brandon P Semel

Virginia Tech: Virginia Polytechnic Institute and State University

Michael J Cherry

Texas A and M University: Texas A\&M University

Tsioriniaina J Ratovoson

Universite d'Antananarivo

Ignacio T Moore

Virginia Tech: Virginia Polytechnic Institute and State University

\section{Research}

Keywords: Movement, space use, foraging, resource selection, Brownian bridge modeling, home range, road avoidance, primates, lemurs

Posted Date: October 25th, 2021

DOI: https://doi.org/10.21203/rs.3.rs-1001185/v1

License: (c) (i) This work is licensed under a Creative Commons Attribution 4.0 International License. Read Full License

Version of Record: A version of this preprint was published at Movement Ecology on April 15th, 2022. See the published version at https://doi.org/10.1186/s40462-022-00320-x. 
1 Environmental and anthropogenic influences of movement and foraging in a critically

2 endangered lemur species, Propithecus tattersalli: implications for habitat conservation

3 planning

4 Short title: Lemur space use and foraging behavior

6 Meredith A. Semel (0000-0003-4317-8602)

7 Department of Biological Sciences, Virginia Tech, Blacksburg, VA 24061 USA

8 Heather N. Abernathy

9 Department of Fish \& Wildlife Conservation, Virginia Tech, Blacksburg, VA 24061

10 USA

11 Brandon P. Semel (0000-0003-3286-0382)

12 Department of Fish \& Wildlife Conservation, Virginia Tech, Blacksburg, VA 24061

13 USA

14 Michael J. Cherry

15 Caesar Kleberg Wildlife Research Institute, Texas A\&M University-Kingsville,

16 Kingsville, TX 78363 USA

17 Tsioriniaina J.C. Ratovoson

18 Department of Zoology and Animal Biodiversity, University of Antananarivo,

19 Antananarivo, Madagascar

20 Ignacio T. Moore

21 Department of Biological Sciences, Virginia Tech, Blacksburg, VA 24061 USA

22 Corresponding Author: Meredith Semel merak91@vt.edu (847) 636-0788 


\section{Abstract}

\section{Background}

26 Wildlife conservation often focuses on establishing protected areas, however, these

27 conservation zones are frequently developed without adequate knowledge of the

28 movement patterns of the species they are designed to protect. Understanding movement

29 and foraging patterns of species in dynamic and diverse habitats can allow managers to

30 develop more effective conservation plans. Threatened lemurs in Madagascar are an

31 example where management plans and protected areas are typically created to encompass

32 large, remaining forests rather than the resource needs of the target species.

\section{Methods}

35 To gain an understanding of golden-crowned sifaka (Propithecus tattersalli) movement

36 patterns, including space use and habitat selection, across their range of inhabited forest

37 types, we combined behavior data with Dynamic Brownian Bridge Movement Models

38 and Resource Selection Functions. We also examined the influence of abiotic, biotic, and

39 anthropogenic factors on home range size, movement rates, and foraging patterns.

40

\section{Results}

42 We found that home range size and movement rates differed between seasons, with

43 increased core area size and movement in the rainy season. Forest type also played a role

44 in foraging behavior with lemur groups in humid forest avoiding roads in both seasons, 
45 groups in the dry deciduous forest avoiding road networks in the rainy season, and groups

46 in the moderate evergreen forest displaying no selection or avoidance of road networks

47 while foraging.

\section{Conclusion}

50 Our study illustrates the importance of studying primate groups across seasons as well as

51 across forest types, as developing conservation plans as a single snapshot can give an

52 inaccurate assessment of their natural behavior and resources needs. More specifically,

53 by understanding how forest type influences golden-crowned sifaka movement and

54 foraging behavior, we can make conservation management plans specific to the

55 individual forest types they inhabit (humid, moderate evergreen, dry deciduous, littoral,

56 etc.), rather than the region as a whole.

\section{$58 \quad$ Key Words}

59 Movement; space use; foraging; resource selection; Brownian bridge modeling; home

60 range; road avoidance; primates; lemurs 


\section{Background}

63

64 Conservation biologists have long recognized the importance of establishing protected

65 areas to facilitate population persistence in landscapes that are threatened by increasing

66 human encroachment, habitat fragmentation, and habitat loss [1-4]. However, efforts to

67 conserve wildlife and preserve biodiversity are often based on an incomplete

68 understanding of animal movement as well as variability in movement patterns among

69 groups or populations that the areas are meant to protect [5]. While a number of studies

70 have demonstrated the relevance of incorporating movement, particularly animal foraging

71 and home range size, into protected area design [6-9], integration between the disciplines

72 of conservation biology and movement (coined "conservation behavior") is limited [10-

73 12]. Yet, knowledge of movement behavior, specifically how, when, and where animals

74 move and forage within their habitat, would illuminate how populations navigate and

75 utilize resources within their environment and thus develop better management plans

$76[13,14]$. Specifically, species, populations, or even groups often respond differently to

77 factors such as seasonality, habitat characteristics, and anthropogenic pressures in

78 different ways and therefore a better understanding of their role is crucial when

79 developing management plans and establishing protected areas.

80

81 In the tropics, seasons are often divided into dry and rainy seasons, with primary

82 productivity varying seasonally as a function of rainfall. This seasonality thus influences

83 the distribution and availability of resources on the landscape and as a result animal 
84 movement strategies shift to increase foraging efficiency [15-17]. For example, the

85 black-fronted titi monkey (Callicebus nigrifons; Nagy-Reis and Setz, 2017) and collared

86 brown lemur (Eulemur collaris; Campera et al., 2014) cope with dry season food

87 shortages by reducing movement rates, while the common bumble bee (Bombus

88 vosnesenskii; Pope and Jha, 2018) and African elephant (Loxodonta africana; Wato et al.,

89 2018), respond by increasing foraging and movement rates. Animals can also cope with

90 dry season conditions by shifting home range size or location [22] and altering time spent

91 foraging [23]. Understanding how seasonal fluctuations influence movement and

92 foraging patterns in free-living animals can allow managers to more effectively design

93 protected areas and protect critical resources [24].

94

95 In addition to abiotic factors, biotic factors such as habitat (forest) type, strongly

96 influence animal movement and foraging [25]. Various studies demonstrate that animals

97 adjust their home range size and foraging patterns in response to habitat type and

98 structure (e.g. Roe deer (Capreolus capreolus); Said and Servanty, 2005) and coyote

99 (Canis latrans); Holzman et al., 1992)) indicating that landscape heterogeneity is a key

100 factor influencing the movement of species. While studies of canids, ungulates, and

101 primates have examined the influence of habitat type on home range size, a large

102 proportion of studies are limited to examining metrics of habitat structure (e.g. forest

103 maturity, vegetation density, food scarcity, microhabitat preference) on animal movement

104 and home range size [28,29]. The benefit of understanding movement behavior across 
105 distinct habitat types is that management strategies can be designed for each habitat type

106 a species occupies.

108 Importantly, anthropogenic influences affect animal movement behaviors, can have

109 deleterious effects on wildlife, and must be considered when establishing protected areas

$110[30,31]$. The presence of humans and road networks may negatively influence animal

111 movement behavior by increasing human-wildlife interactions (e.g., hunting, poaching,

112 vehicle collisions) and pushing animals out of prime habitat [32,33]. Large mammals are

113 especially affected by human encroachment due to their larger home range size, lower

114 population density, more narrow geographic distributions, and large portions of their

115 distributions being shared with humans [34]. For instance, black bears (Ursus

116 americanus) have been found to avoid areas with human development during daylight

117 hours [35] and woodland caribou (Rangifer tarandus caribou) avoid high use roads,

118 mines, and cabins during months of high human activity [36]. Of large mammalian taxa,

119 few studies have examined the influence of human infrastructure on primate movement,

120 although they are often strongly affected by anthropogenic features [37,38].

122 The lemurs of Madagascar face significant anthropogenic threats [39]. Between 1953 and

123 2014, Madagascar lost $44 \%$ of its forests, with $46 \%$ of the remaining forests being

124 located within $100 \mathrm{~m}$ of a forest edge [40]. This high degree of forest destruction and

125 increasing presence of edge forest habitat influences lemur behavior and their ability to

126 meet their nutritional demands. While previous studies have examined lemur home range 
127 size [41,42], dietary flexibility [43], species abundance [44], and reproduction in various

128 environments [45,46], our understanding of lemur movement is limited but members of

129 the genus Propithecus have provided some information. In regard to home range

130 characteristics, diademed sifakas (Propithecus diadema) in humid fragmented habitats

131 had reduced home range size and daily path length and foraged on sub-optimal food

132 items compared to sifaka groups in contiguous forest environments [41]. In contrast,

133 Milne-Edwards' sifakas (Propithecus edwardsi) inhabiting humid logged forests traveled

134 shorter distances each day to feed in a low-quality food environment, yet maintained

135 larger home ranges than conspecifics in contiguous forests [42]. Further, Verreaux's

136 sifakas (Propithecus verreauxi) in Madagascar's dry deciduous forests exhibited

137 significant home range reduction from the rainy to the dry season [47]. While these

138 studies have shed light on Propithecus behavioral responses to abiotic and biotic factors

139 in extremes of the humid-dry forest gradient of forest types, we do not understand how

140 species in the genus Propithecus respond in a moderate forest type. Knowledge of

141 Propithecus movement behavior in regards to these factors would enable us to predict

142 how these lemurs would use a protected area and design a reserve accordingly.

144 Golden-crowned sifaka (Propithecus tattersalli) are a critically endangered lemur

145 endemic to naturally fragmented forests of northeastern Madagascar [48]. Unlike the

146 other eight species of sifaka (Propithecus spp.) on Madagascar that are restricted to dry

147 or humid forest types, $P$. tattersalli inhabit a range of forest types [49,50]. Variation of

148 habitable forest types makes them a unique opportunity to examine the influence of 
149 seasonality, forest type, and anthropogenic factors on movement and foraging behavior in

150 a primate. Studies of golden-crowned sifaka have documented a major decline in the

151 population in the last decade and informed researchers of the natural fragmentation of the

152 landscape, yet no previous study has examined the influence of movement on space use

153 and foraging tree selection across their range (Quéméré et al., 2012; Salmona et al.,

154 2017). An understanding of how abiotic, biotic, and anthropogenic factors influence

155 golden-crowned sifaka space use and foraging throughout their range would allow

156 species management plans to be made for populations within each particular forest type

157 occupied rather than the species as a whole.

159 In this study, we analyzed location and foraging behavior of six golden-crowned sifaka

160 groups to evaluate the effects of abiotic (seasonality; rainy and dry season), biotic (forest

161 type; humid, moderate evergreen, and dry deciduous forests), and anthropogenic

162 (fragmentation; edge and interior forests) factors on their movement patterns and space

163 use. Approaches to studying nonhuman primate space use typically are limited to

164 examining daily path length and home range overlap through the use of area estimators

165 (MCP, line-based kernel density, etc.; (e.g. Lehmann and Boesch, 2002; Steiniger and

166 Hunter, 2013). More modern and sophisticated approaches including Dynamic Brownian

167 Bridge movement models (DBBMM) and Bayesian methods [55,56], reduce the

168 likelihood of both Type I and Type II errors which can bias our understanding of animal

169 space use and habitat selection [57]. Thus, to estimate space use we used DBBMM which

170 incorporated temporal and behavioral characteristics of movement trajectories into 
171 estimation of an animal's home range [58]. For our first objective we predicted that

172 seasonal movement rates would be greater in the rainy season, humid forests, and edge

173 forests compared to drier more interior forests. Second, we predicted that home range

174 size and core area range size would be larger in the rainy season, in edge forests, and in

175 the humid forest compared to drier and interior forests. We also predicted that sifaka

176 groups in edge forests would exhibit less core area range overlap (between the rainy and

177 dry seasons) than interior forest groups. Third, we predicted that sifakas would select the

178 largest feeding trees within their home ranges and avoid locations near human settlements

179 or manmade structures.

180

181 Methods

182

\section{Study Area}

185 Research was conducted in the Loky-Manambato Protected Area of northeastern

186 Madagascar (Fig. 1). This protected area encompasses a unique biogeographical

187 transition zone from Madagascar's northern and western dry deciduous forests to

188 southern humid forests. The Loky-Manambato region contains a mosaic of various forest

189 types including dry deciduous, dry evergreen, humid, and littoral forests separated by

190 agricultural areas and savanna (Quéméré et al., 2012). The region experiences a four-

191 month rainy season occurring from December to March followed by an eight-month dry 
192 season [59]. The study sites include three distinct forest types: a humid forest, moderate

193 evergreen forest, and dry deciduous forest.

\section{Study Species and Subjects}

197 Golden-crowned sifaka live in semi-cohesive social groups ranging in size from 3-12

198 individuals with one or more adult males, several adult females, and several immature

199 individuals of both sexes. Group members typically travel in a coordinated fashion and

200 generally remain in visual or auditory contact with at least one other group member [59].

201 Thus, we assumed that all animals within a given social group share a home range, and

202 therefore treated each group as a unit of analysis in this study. Golden-crowned sifaka are

203 frugo-folivores, but also consume seeds, petioles, buds, flowers, and bark.

205 We studied six groups of habituated golden-crowned sifaka distributed across the three

206 distinct forest types (two groups each in humid, moderate evergreen, and dry deciduous

207 forests) in the Loky-Manambato Protected Area. We selected three of the 11 large forest

208 fragments containing golden-crowned sifaka due to their accessibility: Binara (humid),

209 Bekaraoka (moderate evergreen), and Solanamampilana (dry deciduous) (Figure 1).

210 Within each forest type, we followed one group in primary forest towards the center of

211 the forest (hereafter interior; characterized by lemurs having a home range at least 300

212 meters from the forest edge) and one group on the edge of the forest fragment (hereafter 
213 edge; characterized by having a home range adjacent to the forest edge). Average group

214 size was six individuals and ranged from five to eight (Table 1).
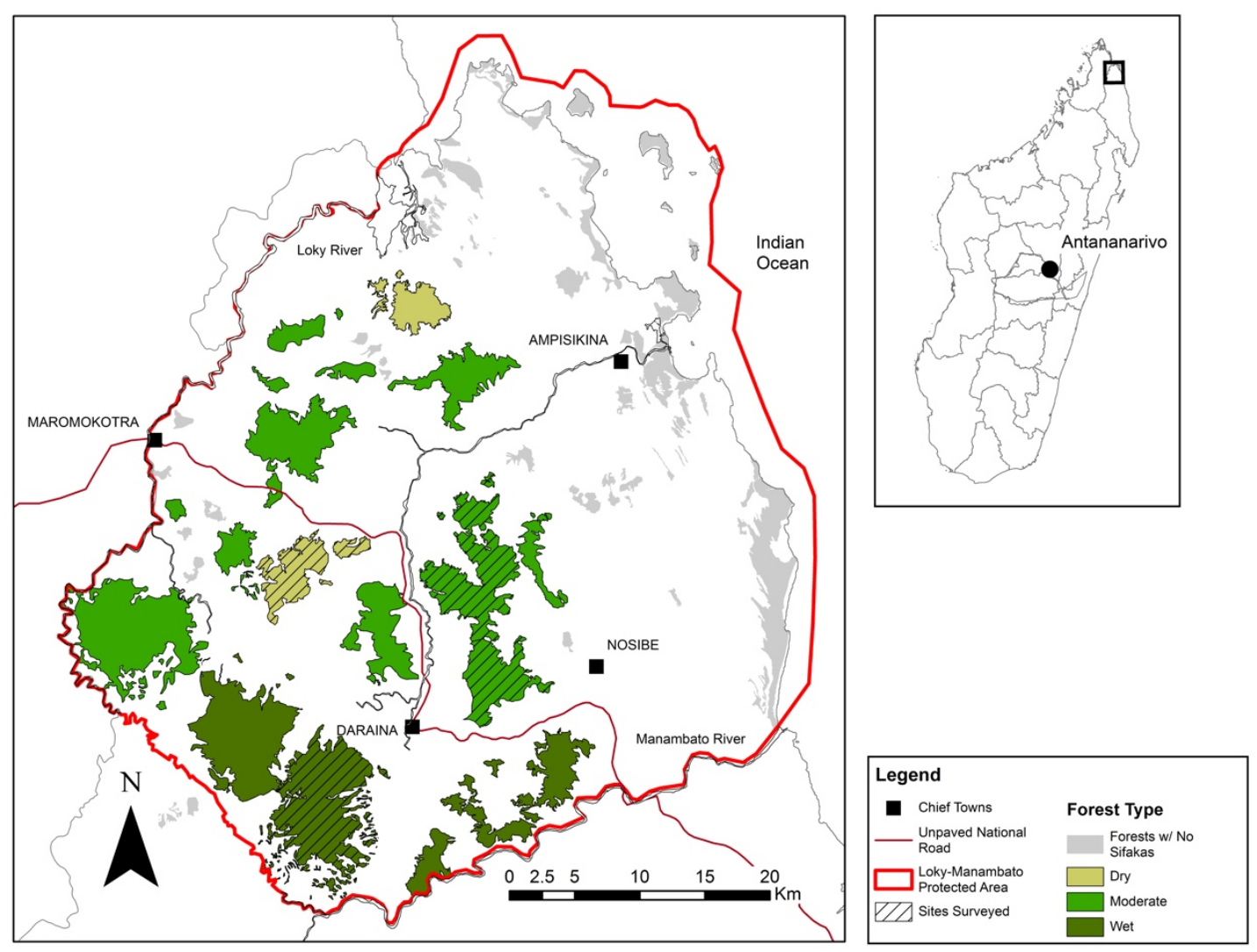

216 Fig. 1. Study area in the Loky-Manambato Protected Area of northern Madagascar. The

217 thin red line depicts the unpaved national road in the region. The three forest fragments

218 surveyed are denoted by hatched black lines and are colored based on forest type. 
224 Table 1. Composition of focal groups within each forest fragment, forest type, and forest 225 fragmentation classification.

\begin{tabular}{lccc}
\hline Forest Fragment & Forest Type & Forest Location & Group Size \\
\hline Binara & Humid & Interior & 7 \\
Binara & Humid & Edge & 5 \\
Bekaraoka & Moderate Evergreen & Interior & 7 \\
Bekaraoka & Moderate Evergreen & Edge & 8 \\
Solanamampilana & Dry Deciduous & Interior & 5 \\
Solanamampilana & Dry Deciduous & Edge & 5 \\
\hline
\end{tabular}

228 Group Location Data

230 We collected golden-crowned sifaka group location data during two periods, February-

231 April 2019 (rainy season) and June-August 2019 (dry season). We followed groups from

232 sleep tree to sleep tree ( $\sim 13$ hours per day) and collected location data at 15-minute

233 intervals. In addition to daytime activity, golden-crowned sifaka are known to exhibit

234 nocturnal movements, specifically during periods of bright moon light [60], and thus

235 groups were not always located in the same sleep tree the following morning. In these

236 instances, we reestablished contact with the group as quickly as possible. Group locations

237 were recorded using a GPS receiver (Garmin 64s), using the Universal Transverse 
238 Mercator coordinate system (zone 39L), and points were logged at the group's

239 approximate geometric center. If no animals were visible at the 15-minute interval,

240 observers waited to establish visual contact with the social group before recording any

241 locations.

242

\section{Foraging and Landscape Data}

245 We recorded foraging data at the same 15-minute intervals using scan sampling to record

246 the behavior, height in the tree, and nearest neighbor of each individual in a group [61]. If

247 an individual was actively feeding during the scan, the plant species and part (e.g.,

248 young/mature leaf, leaf petiole, un/ripe fruit, seed, or flower) were identified, GPS

249 location recorded, and data concerning tree species, size, and current phenology

250 collected. In addition to collecting foraging data specific to each of the lemur groups, we

251 also collected general landscape data throughout each of the six lemur home ranges in

252 both the rainy and dry season. We did this by randomly generating forty GPS points

253 within each of the six home ranges (in both seasons) and collected data from potential

254 feeding trees (species, size, phenology) within 5 meters of each location. This allowed us

255 to gain an understanding of the entire landscape of all six home ranges, not just the

256 specific feeding trees utilized by each of the groups.

\section{Home Range Estimation}


260 Utilization distributions (i.e., 95\% isopleth, hereafter home ranges and 50\% isopleth,

261 hereafter core area) were estimated for each golden-crowned sifaka group using Dynamic

262 Brownian Bridge Movement Models (DBBMM); [58]. Home range DBBMMs use

263 behavior and movement trajectory data of the animal group that is collected in sequential

264 relocation studies. This method provides a spatially explicit model, which describes the

265 probability of the given animal group occurring in a given location during a specified

266 period. This approach also accounts for temporal autocorrelation, spatial uncertainty,

267 irregularly sampled data, and shifts in an animal's behavior (resting, foraging,

268 thermoregulating, corridor use, etc.), making it specifically applicable to studies of group

269 living primates $[57,58,62]$. Using DBBMMs to estimate group home ranges requires a

270 Brownian motion variance parameter ( $\sigma^{2}$, in meters), which quantifies the degree of

271 diffusion or irregularity of an animal's path [58]. A moving window analysis identifies

272 changes in the movement behavior and estimates $\sigma^{2}$ for each step. The size of the moving

273 window must include an odd number of GPS locations, because the $\sigma^{2}$ parameter is

274 estimated using a "leave-one-method", and a margin of greater than three locations

275 bounding each end of the window in which no behavioral changes can occur [58]. We

276 parameterized the DBBMM with a 21-step window size, a 9-step margin size, and a $15 \mathrm{~m}$

277 location error for all lemur groups, as visual inspection indicated these settings were

278 sufficient to identify changes in home range size and overall animal movement [58].

279 Home ranges were estimated for each lemur group using the DBBMM function in $\mathrm{R}$

280 package 'move' $[63,64]$. We conducted a three-way analysis of variance (ANOVA)

281 predicting for both $50 \%$ (core area) and $95 \%$ home ranges, respectively, to determine if 
282 season, forest type, interior or edge forests, and the interaction of forest type and season

283 influenced core area and home range size. All analyses were conducted in version 3.5.1

284 of program R [65]. We used Akaike's Information Criterion (AICc) to identify a top

285 model from the set of candidate ANOVA models [66].

286

287 Core Area Overlap

288

289 To determine the percent of joint home range overlap between the rainy and dry season

290 home ranges, we calculated the total area of each home range and then divided the area of

291 overlap between seasons by the total home range size [67]. Possible core area overlap

292 ranged from $0 \%$ overlap, indicating no shared space use between seasons, to $100 \%$

293 overlap, indicating the dry and rainy season ranges overlapped completely. To determine

294 if the home range overlap between the rainy and dry seasons varied as a function of

295 fragmentation types (edge or interior), we conducted an unpaired two-sample t-test

296 assuming equal variances. We tested the variance assumption of our t-test using an F-test,

297 'var.test', in program R. Finally, to determine if the core area overlap between the rainy

298 and dry seasons varied as a function of forest type (humid, moderate, or dry), we

299 conducted a one-way ANOVA comparing core area and 95\% home range and core area

300 as a function of degree of forest type. All analyses were conducted in version 3.6.1 of

301 program R [65].

302

303 Movement Rates 
305 We calculated movement rates (meters/hour) for each lemur group using the collected

306 relocation data. The step length (i.e., the distance between sequential locations) was

307 divided by the time elapsed between each sequential location to calculate speed for each

308 golden-crowned sifaka group to characterize movement rates. To determine how

309 movement varied across season (rainy and dry), forest fragmentation (edge or interior),

310 and forest types (humid, moderate evergreen, and dry deciduous) we calculated

311 movement rates at both the daily and seasonal scale.

312

313 Daily movement rates were bootstrapped to calculate a mean for each observational day.

314 Bootstrapping is a process that involves repeatedly drawing independent samples from a

315 data set $(\mathrm{x})$ to create bootstrap data sets $\left(\mathrm{x}^{1}, \mathrm{x}^{2}, \ldots, \mathrm{x}^{\mathrm{n}}\right)$. Our samples were performed with

316 replacement which allowed for the same observation to be sampled more than once such

317 that each bootstrapped sample was the same length as our raw lemur speed data (m/hour).

318 To calculate seasonal movement rates $(\widehat{S M R})$, we drew 1000 independent samples

$319\left(\hat{\alpha}^{1}, \hat{\alpha}^{2}, \ldots, \hat{\alpha}^{B}\right)$ to calculate means and standard error $\left(\widehat{S E}_{B}\right)$, which we then used to

320 generate $95 \%$ confidence intervals for comparison of means among seasons and groups,

$$
\widehat{S E}_{B}=\sqrt{\frac{\sum_{b=1}^{B}\left(\widehat{\alpha}^{i}-\widehat{\alpha}^{B}\right)^{2}}{(B-1)}}
$$

322 where $\widehat{S E}_{B}$ served as our estimate of the standard error of $\hat{\alpha}$ estimated from the raw lemur

323 speed data ( $\mathrm{m} /$ hour). We calculated seasonal movements rates using the bootstrapping

324 approach outlined above but employed the method for each observation season. 
326 To determine how environmental variables influenced daily movement rates, we fit linear

327 mixed effects models to predict movement rate as a function of all combinations of

328 season (rainy or dry), forest fragmentation (edge or interior), and forest type (humid,

329 moderate evergreen, and dry deciduous), while treating forest type-forest fragmentation

330 per group intercepts as random effects [68]. We used the Satterthwaite method to

331 approximate the degrees of freedom and computed p-values for direct effects and

332 interactions using t-statistics.

334 Finally, to determine how environmental variables influenced seasonal movement rates,

335 we conducted a three-way ANOVA seasonal movement rates as a function of forest type

336 (dry, humid, and wet), forest fragmentation (edge and interior), and season (dry and

337 rainy). All analyses were conducted in version 3.6.1 of program R [65]. We used

338 Akaike's Information Criterion corrected for small sample size (AICc) to identify a top

339 model from the set of candidate models [69]. All analyses were conducted in version

$340 \quad 3.6 .1$ of program $\mathrm{R}[65,68]$.

\section{Habitat Selection}

344 To quantify habitat selection of golden-crowned sifaka groups, in relation to tree size and

345 proximity to anthropogenic factors, we fit a Resource Selection Function (RSF) using a

346 use-available design. A RSF is defined as any function producing a value proportional to 
347 the probability of selection of a given habitat $[70,71]$. Any estimate derived from an RSF

348 is dependent on the definition of available habitats [55,70,72]. For our RSF, selection by

349 golden-crowned sifaka availability was considered within home range selection

350 (Johnson's third order; Johnson 1980) as defined by a 95\% seasonal home range (i.e.,

$35195 \%$ isopleth) using DBBMMs. Within our seasonal home ranges, we characterized

352 availability by systematically identifying available locations at intervals of $10 \mathrm{~m}$, as this

353 was the spatial resolution of all spatial data used in the RSF [73].

355 We created our RSFs by fitting generalized linear mixed-effects model (GLMM) with a

356 binomial link function, which included a group-specific (forest type and fragmentation

357 type) random intercept term to account for non-independence of habitat associations

358 within groups [74,75]. For our RSF, we used GPS locations of all feeding trees that

359 golden-crowned sifaka utilized during the rainy and dry field seasons and possible

360 locations within their known home ranges. We extracted tree basal area (cross-sectional

361 area of trees at breast height), Euclidian distance to village, road, and habitat fragment

362 edge for each golden-crowned sifaka feeding tree and each available location. These data

363 were generated using satellite imagery and habitat sampling of resources within each of

364 the six lemur home ranges.

365

366 To relate tree basal area and crown volume to lemur GPS location data, we created

367 continuous surfaces of tree basal area and crown volume estimates across our study area

368 by using inverse distance weighting (IDW) interpolation in the package gstat [76] in 
369 version 3.6.1 of program R [65]. IDW uses a weighted average of estimates from nearby

370 sampling locations to predict tree basal area and crown volume estimates to the

371 surrounding pixels of a sampling location composed of user-specified areas [77]. Our

372 user-specified areas of inference were $169 \mathrm{~m}^{2}$ because it most closely matched the mean

373 distance between vegetation sampling locations (148.85 m). This interpolation process

374 provided spatially explicit estimates of tree basal area and crown volume estimates which

375 we could then associate with our lemur GPS data.

376

377 To examine if lemur habitat selection varied across forest types and seasons, we

378 developed candidate models using various combinations of distance to habitat feature

379 (i.e., village, road, and habitat fragment), and basal area, and used Akaike's Information

380 Criterion (AICc) to identify a top model from the set of candidate models [66] to

381 determine: 1) if differences in habitat selection vary as a function of forest type, and 2) if

382 differences in habitat selection vary as a function of season at each site. To account for

383 behavioral differences in lemur groups, we accounted for random effects using an

384 'animal id' that consisted of each lemur group's respective forest type (humid, dry, or

385 moderate), forest fragmentation classification (edge or interior), and season (rainy or

386 dry). No environmental variables used in model development exhibited high correlation

387 (i.e., $|r|>0.7)$. All coefficients were estimated using the "lme4" package for R 3.0.1

$388 \quad[65,68]$.

389

390 


\section{Results}

392

\section{Home range size estimation}

394

395 Overall, home range sizes (95\% utilization distribution) for golden-crowned sifaka

396 groups in the Loky-Manambato Protected Area were highly variable and ranged from

$3972.78-31.56$ hectares (Table 2). Our top ANOVA model (Table 3), revealed that golden-

398 crowned sifaka core areas $(50 \%$ home range $)$ varied with season $(\mathrm{p}=0.003, \mathrm{~F}=14.65$,

$399 \mathrm{df}=1$, residual $\mathrm{df}=10$, residual $\mathrm{SE}=0.004)$ with core areas being larger in the rainy

400 season (average of 1.80 hectares in the rainy season, 0.81 hectares in the dry season).

401 However, while our ANOVA model candidate set for home ranges (95\% home range) did

402 include season as a top model, suggesting a trend towards increased home range size in

403 the rainy season (dry or rainy; $\mathrm{p}=0.08, \mathrm{~F}=3.671, \mathrm{df}=1$, residual $\mathrm{df}=10, \mathrm{SE}=0.08$ ), it

404 was no better than our null model when considering a delta AIC of 2 (Table 4).

405

406 Seasonal Core Area Overlap

407

408 Seasonal overlap of the $50 \%$ home range area varied from $17 \%$ to $54 \%$ overlap (Table 2 ,

409 Figure 2). Core area overlap between the rainy and dry season did not vary with forest

410 type (core area $-\mathrm{p}=0.702, \mathrm{~F}=0.393, \mathrm{df}=2$, residual $\mathrm{df}=3, \mathrm{SE}=0.003$; home range -

$411 \mathrm{p}=0.394, \mathrm{~F}=1.29, \mathrm{df}=2$, residual $\mathrm{df}=2$, residual $\mathrm{SE}=0.001)$ or forest fragmentation 
412 (core area $-\mathrm{p}=0.365, \mathrm{~F}=1.04, \mathrm{df}=1$, residual $\mathrm{df}=4$, residual $\mathrm{SE}<0.001$; home range -

$413 \mathrm{p}=0.219, \mathrm{~F}=2.21 . \mathrm{df}=1$, residual $\mathrm{df}=4$, residual $\mathrm{SE}=0.02$ ).

414

415

416

417

418

419

420

421

422

423

424

425

426

427

428 Table 2. Home range sizes (50\% and 95\% isopleth (UD: utilization distribution)) of

429 sifaka groups in the rainy and dry season. The three forest fragments differ in forest type

430 (Moderate; Bekaraoka, Humid; Binara, Dry; Sola) and forest fragmentation (interior;

431 edge).

432 


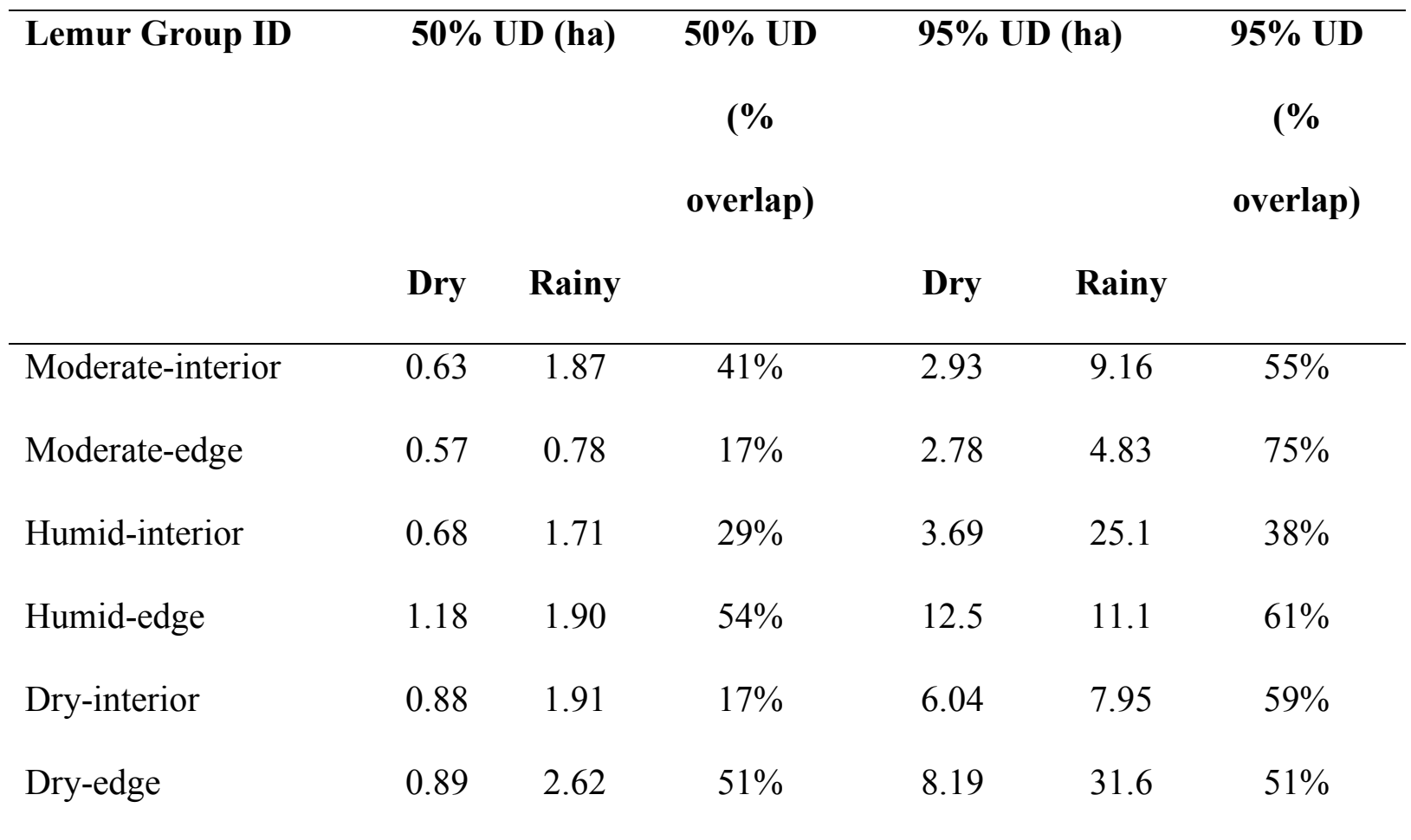

433

441 Table 3: Models, the number of parameters (K), log-likelihood (LL), the relative 442 difference in AICc values compared to the top-ranked model ( $\triangle \mathrm{AICc}$ ), and the AIC 443 model weights $(\mathrm{W})$ of the model-selection procedure examining core area size $(50 \%$ 444 isopleth) of lemur groups. 


\begin{tabular}{lccccc}
\hline Model & $\mathrm{K}$ & $\mathrm{LL}$ & $\mathrm{AICc}$ & $\Delta \mathrm{AICc}$ & $\mathrm{W}$ \\
\hline season & 1 & 48.946 & -88.9 & 0 & 0.828 \\
fragmentation + season & 2 & 48.963 & -84.2 & 4.68 & 0.08 \\
forest type + season & 2 & 51.882 & -83.8 & 5.13 & 0.064 \\
null & 0 & 43.533 & -81.7 & 7.16 & 0.023 \\
fragmentation & 1 & 43.54 & -78.1 & 10.81 & 0.004 \\
forest type & 1 & 44.558 & -75.4 & 13.49 & 0.001 \\
forest type + season + & & & & & \\
fragmentation & 3 & 51.91 & -75 & 13.87 & 0.001 \\
forest type + fragmentation & 2 & 44.566 & -69.1 & 19.76 & 0 \\
\hline
\end{tabular}

447 Table 4: Models, the number of parameters (K), log-likelihood (LL), the relative

448 difference in AICc values compared to the top-ranked model ( $\triangle \mathrm{AICc})$, and the AIC

449 model weights (W) of the model-selection procedure examining home range size $(95 \%$

450 isopleth) of lemur groups.

\begin{tabular}{|c|c|c|c|c|c|}
\hline Model & $\mathrm{K}$ & LL & AICc & $\triangle \mathrm{AICc}$ & $\mathrm{W}$ \\
\hline season & 1 & 14.266 & -19.5 & 0 & 0.427 \\
\hline null & 0 & 12.389 & -19.4 & 0.09 & 0.409 \\
\hline fragmentation & 1 & 12.535 & -16.1 & 3.46 & 0.076 \\
\hline fragmentation + season & 2 & 14.466 & -15.2 & 4.31 & 0.049 \\
\hline forest type & 1 & 13.793 & -13.9 & 5.66 & 0.025 \\
\hline forest type + season & 2 & 16.279 & -12.6 & 6.97 & 0.013 \\
\hline forest type + fragmentation & 2 & 13.978 & -8 & 11.58 & 0.001 \\
\hline forest type + fragmentation + season & 3 & 16.562 & -4.3 & 15.21 & 0 \\
\hline
\end{tabular}



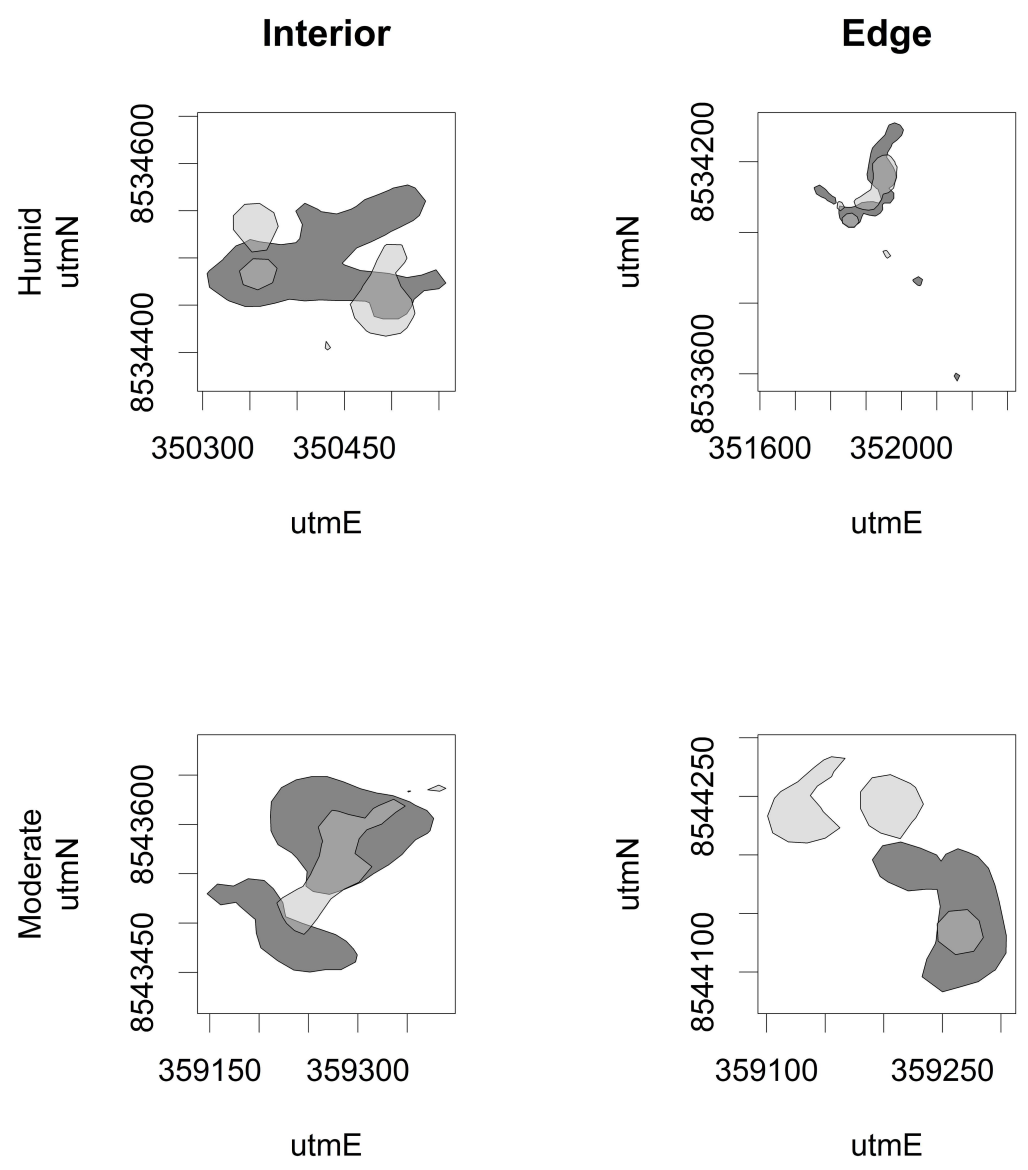

453
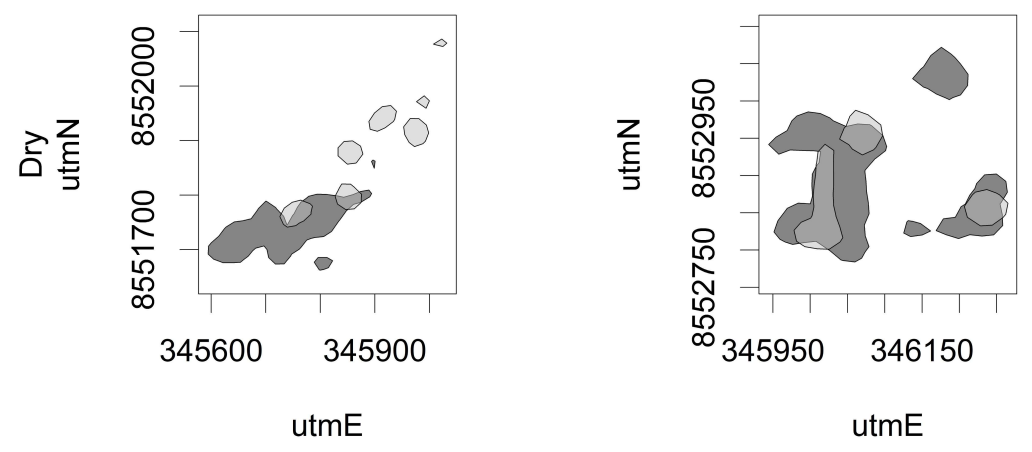
454 Fig. 2. Brownian bridge utilization distribution (50\% isopleth) depicting core area use for 455 golden-crowned sifaka groups between the rainy (dark gray) and dry (light gray) season.

456 Overlapping areas are occupied during both seasons. The six figures display the seasonal

457 home ranges for all six lemur groups followed. The columns indicate forest

458 fragmentation classification (interior or edge) and the rows indicate the occupied forest

459 type (humid, moderate, or dry) of all six lemur groups.

461 Daily and Seasonal Movement Rates

462

463 Our top model (Table 5) indicated that seasonal movement rates varied as a function of 464 season (Sum Squares $=0.405,95 \%$ CI $[0.13,0.65], F=11.27, \mathrm{df}=1, \mathrm{p}=0.007$, residual $\mathrm{df}=$ 46510 , residual $\mathrm{SE}=0.04$ ), with higher rates in the rainy season (rainy season: $83.47 \mathrm{~m} / \mathrm{h}$;

466 dry season: $56.70 \mathrm{~m} / \mathrm{h}$ ). When investigating daily movement rates, our mixed effects

467 linear model analysis supported our seasonal movement results, as the top model

468 included season; however, there was not support for effects of forest type or forest

469 fragmentation $(\beta=0.36,95 \%$ CI $[0.11,0.60] ; p=0.019$; Table 6 , Figure 3$)$. 
476 Table 5: Competing models, the log-likelihood (LL), the number of parameters in the

477 model (K), the relative difference in AICc values compared to the top-ranked model

478 ( $\triangle \mathrm{AICc}$ ), and the AIC model weights $(\mathrm{W})$ of the model-selection procedure examining

479 seasonal movement rates of lemur groups.

\begin{tabular}{lcccc}
\hline Model & LL & AICc & $\Delta \mathrm{AICc}$ & $\mathrm{W}$ \\
\hline season & 3.382 & 2.2 & 0 & 0.733 \\
fragmentation + season & 4.394 & 4.9 & 2.69 & 0.191 \\
null & -1.145 & 7.6 & 5.39 & 0.05 \\
fragmentation & -0.691 & 10.4 & 8.15 & 0.012 \\
forest type + season & 4.779 & 10.4 & 8.21 & 0.012 \\
forest type & -0.529 & 14.8 & 12.54 & 0.001 \\
forest type + season + fragmentation & 6.086 & 16.6 & 14.39 & 0.001 \\
forest type + fragmentation & -0.023 & 20 & 17.81 & 0 \\
forest type + season + forest type*season & 6.158 & 29.7 & 27.45 & 0 \\
forest type + fragmentation + season + forest & & & & \\
type* season & 7.856 & 48.3 & 46.05 & 0 \\
\hline
\end{tabular}

481 Table 6. Competing models, the log-likelihood (LL), the number of parameters in the

482 model $(\mathrm{K})$, the relative difference in AICc values compared to the top-ranked model

483 ( $\triangle \mathrm{AICc}$ ), and the AIC model weights $(\mathrm{W})$ of the model-selection procedure examining

484 daily movement rates of lemur groups.

\begin{tabular}{lccccc}
\hline Model & $\mathrm{K}$ & $\mathrm{LL}$ & $\mathrm{AICc}$ & $\Delta \mathrm{AICc}$ & $\mathrm{W}$ \\
\hline season & 1 & -27.381 & 63.3 & 0.00 & 0.586 \\
null & 0 & -29.393 & 65.1 & 1.82 & 0.236 \\
fragmentation + season & 2 & -28.186 & 67.1 & 3.87 & 0.085 \\
fragmentation & 1 & -30.082 & 68.7 & 5.40 & 0.039 \\
forest type + season & 2 & -28.022 & 69.1 & 5.87 & 0.031 \\
forest type & 1 & -30.101 & 71.0 & 7.70 & 0.012 \\
forest type + season + fragmentation & 3 & -28.845 & 73.2 & 9.89 & 0.004 \\
forest type + season + forest & 4 & -27.815 & 73.6 & 10.28 & 0.003 \\
type* season & & & & & \\
forest type + fragmentation & 2 & -30.777 & 74.6 & 11.38 & 0.002 \\
Global & 5 & -28.634 & 77.7 & 14.43 & 0.000 \\
\hline
\end{tabular}




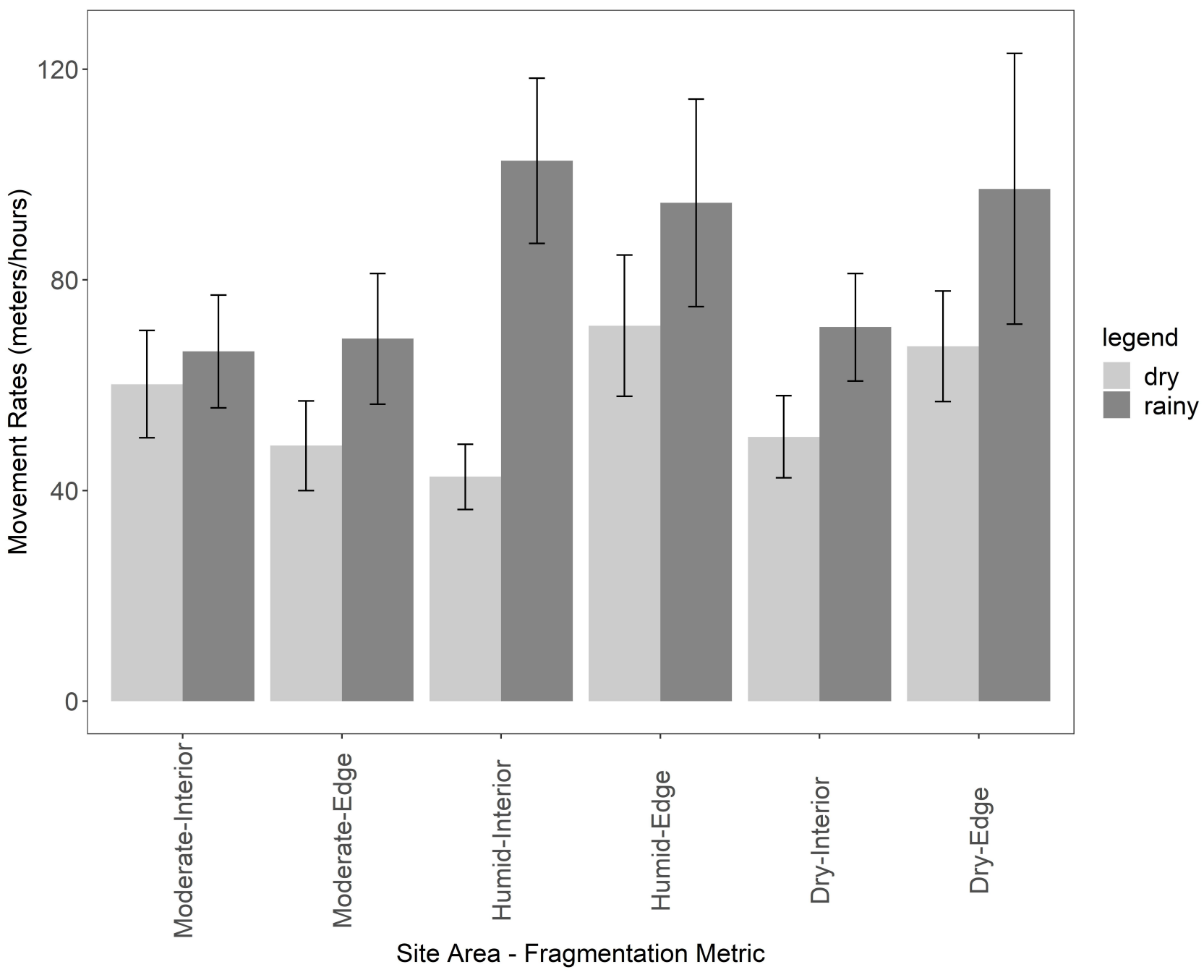

488 Fig. 3. Seasonal movement rates (meters/hour) of golden-crowned sifaka groups using

489 relocation data collected every 15 minutes. The step length (e.g., the distance between

490 sequential locations) was divided by the time elapsed between each step to calculate

491 speed for each lemur group. Data were collected during the dry season (June-August

492 2019) and the rainy season (February-April 2019). Black lines correspond to 95\%

493 confidence intervals. 


\section{Habitat Selection}

497 We found that lemur habitat selection varied with forest type (Table 7) and within forest 498 type, selection varied by season (Table 8, Tables S1 - S3). Thus, to make inferences

499 about differences in selection across forest type and season, we parsed the data into forest

500 type and then again into season.

501

502 We found that lemur groups in the humid forests selected feeding trees characterized with 503 greater crown volume $(\beta=-5.0$, s.e. $\pm 1.23, p<0.001)$, closer to villages $(\beta=-0.76$, s.e. \pm

$5040.30, p=0.01)$, and closer to the forest edge $(\beta=-1.04$, s.e. $\pm 0.17, p<0.001)$, and

505 avoided locations near roads $(\beta=2.79$, s.e. $\pm 0.93, p=0.003)$ in the dry season. In the

506 rainy season groups in humid forests selected locations with greater tree basal area $(\beta=$

5070.085$, s.e. $\pm 0.04, p=0.049)$ and greater crown volume $(\beta=1.34$, s.e. $\pm 0.06, p<0.001)$

508 that were closer to villages $(\beta=-1.28$, s.e. $\pm 0.19, \mathrm{p}<0.001)$, and forest edges $(\beta=-0.24$,

509 s.e. $\pm 0.05, p<0.001)$, and avoided habitats near roads $(\beta=3.26$, s.e. $\pm 0.73, p<0.001)$.

510 While the effects of crown volume, villages, forest edges and roads were the same across

511 seasons, these effects were stronger in the rainy season (Table 8; Figure 4).

513 Lemur groups in moderate evergreen forests selected locations with greater crown

514 volume $(\beta=0.52$, s.e. $\pm 0.07, \mathrm{p}<0.001)$, greater tree basal area $(\beta=0.35$, s.e. $\pm 0.17, \mathrm{p}=$

$5150.03)$, and locations farther from villages $(\beta=1.30$, s.e. $\pm 0.32, p<0.001)$ in the dry 
516 season. Selection of locations closer to the forest edge approached significance ( $\beta=$

$517-1.25$, s.e. $\pm 0.68, p=0.065)$. In the rainy season, troops selected feeding trees with 518 greater tree crown volume $(\beta=1.24$, s.e. $\pm 0.07, \mathrm{p}<0.001)$ and greater tree basal area $(\beta=$

5190.55 , s.e. $\pm 0.19, \mathrm{p}=0.003)$ and avoided habitats closer to villages $(\beta=1.91$, s.e. \pm 0.38 ,

$520 \mathrm{p}<0.001)$. Avoidance of the forest edge approached significance $(\beta=-2.76$, s.e. $\pm 1.5, p$

$521=0.069 ;$ Table 8; Figure 4).

522

523 Finally, we found that groups in dry deciduous forests selected greater crown volume ( $\beta$

$524=1.22$, s.e. $\pm 0.45, \mathrm{p}<0.001)$. During the rainy season, groups in dry forest selected

525 locations with greater crown volume $(\beta=1.04$, s.e. $\pm 0.12, \mathrm{p}<0.001)$ and greater tree

526 basal area $(\beta=2.89$, s.e. \pm 0.73 , $\mathrm{p}<0.001)$, and avoided habitat closer to villages $(\beta=$

5273.06 , s.e. $\pm 0.74, p<0.001)$ and roads $(\beta=2.42$, s.e. $\pm 0.50, p<0.001$; Table 8; Figure 4$)$.

528

529

530

531

532

533

534

535

536 
537 Table 7. Competitive models AIC table depicting differences in foraging tree selection 538 among lemurs occupying different forest types. Competitive models, the number of

539 parameters $(\mathrm{K})$, the relative difference in AIC values compared to the top ranked model

540 ( $\triangle \mathrm{AIC}$ ), the AIC weights (W), and the log-likelihood (LL) of the model-selection

541 procedure examining foraging tree selection of lemurs based on occupied forest type

542 (humid, moderate, and dry). CV: Crown Volume, TBA: Tree basal area, V: Distance to

543 village, R: Distance to roads, F: Distance to forest edge, FT: Forest type. Based on the

544 models, forest types could not be grouped and were parsed to make assumptions.

\begin{tabular}{lccccc}
\hline & $\mathrm{K}$ & AIC & $\Delta$ AIC & $\mathrm{W}$ & $\mathrm{LL}$ \\
\hline$(\mathrm{CV}+\mathrm{TBA}+\mathrm{V}+\mathrm{R}+\mathrm{F}) * \mathrm{FT}$ & 19 & 11353.62 & 0 & 1 & -5657.81 \\
$\mathrm{CV}+\mathrm{TBA}+\mathrm{V}+\mathrm{R}+\mathrm{F}$ & 7 & 11425.18 & 71.56 & 0 & -5705.59 \\
\hline
\end{tabular}


546 Table 8. Competitive models AIC table of lemur foraging tree selection based on occupied forest type. Competitive models, the

547 number of parameters $(\mathrm{K})$, the relative difference in AIC values compared to the top ranked model ( $\triangle \mathrm{AIC})$, the AIC weights (W), and

548 the log-likelihood (LL) of the model-selection procedure examining foraging tree selection of lemurs based on occupied forest type

549 (humid, moderate, and dry). CV: Crown Volume, TBA: Tree basal area, V: Distance to village, R: Distance to roads, F: Distance to

550 forest edge, FT: Forest type.

\begin{tabular}{lccccc}
\hline \multicolumn{7}{c}{ Humid Forest } & & & \\
\hline \hline & $\mathrm{K}$ & AIC & $\Delta$ AIC & W & LL \\
$(\mathrm{CV}+\mathrm{TBA}+\mathrm{V}+\mathrm{R}+\mathrm{F}) *$ Season & 13 & 4158.31 & 0 & 1 & -2066.15 \\
$\mathrm{CV}+\mathrm{TBA}+\mathrm{V}+\mathrm{R}+\mathrm{F}$ & 7 & 4206.98 & 48.68 & 0 & -2096.49 \\
\hline \hline & Moderate Forest & & & \\
\hline & $\mathrm{K}$ & AIC & $\Delta$ AIC & W & LL \\
$(\mathrm{CV}+\mathrm{TBA}+\mathrm{V}+\mathrm{R}+\mathrm{F})^{*}$ Season & 13 & 2944.24 & 0 & 1 & -1459.12 \\
$\mathrm{CV}+\mathrm{TBA}+\mathrm{V}+\mathrm{R}+\mathrm{F}$ & 7 & 3043.27 & 99.04 & 0 & -1514.64 \\
\hline \hline & Dry Forest & & & \\
\hline & $\mathrm{K}$ & AIC & $\Delta$ AIC & W & LL \\
$(\mathrm{CV}+\mathrm{TBA}+\mathrm{V}+\mathrm{R}+\mathrm{F})^{*}$ Season & 13 & 4085.42 & 0 & 1 & -2029.71 \\
$\mathrm{CV}+\mathrm{TBA}+\mathrm{V}+\mathrm{R}+\mathrm{F}$ & 7 & 4105.11 & 19.7 & 0 & -2045.56 \\
\hline
\end{tabular}

551 


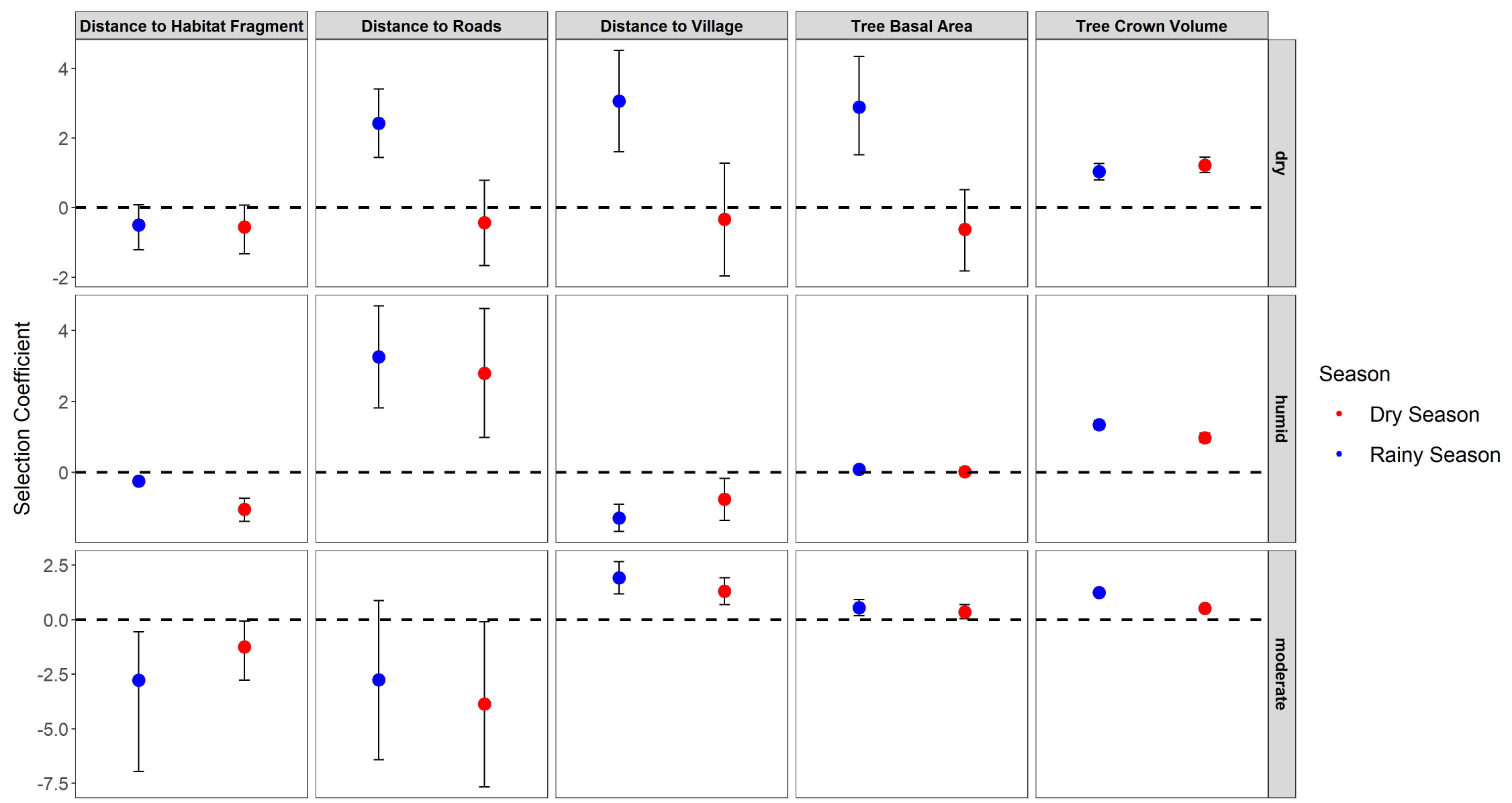

556 Fig. 4. Selection coefficient plot for golden-crowned sifakas in the dry and rainy season within the three forest types. This coefficient

557 plot displays beta estimates for tree basal area and tree crown volume and distance to habitat fragment, roads, and villages. Blue points

558 represent habitat selection during the rainy season and red points represent habitat selection during the dry season. Solid lines above

559 and below each point represent the $95 \%$ confidence intervals around each beta estimate. 
562 Our study shows three primary results. First, golden-crowned sifaka movement rates are greater

563 in the rainy season and in the humid forest type. Second, variation in climatic conditions (rainy

564 vs. dry season) influences lemur movement, with core area range sizes being larger in the rainy

565 season. Third, human disturbance influences lemur spatial ecology with lemurs preferentially

566 selecting foraging locations where larger trees are present. We also detected variation in

567 behavioral responses to villages, road networks, and the forest edge. Lemurs in humid and dry

568 deciduous forest fragments specifically avoided locations near road networks in both the dry and

569 rainy seasons, while lemurs in the moderate evergreen forest did not select or avoid locations

570 near road networks. In sum, groups of golden-crowned sifaka show marked variation in

571 behavioral responses to human disturbance, but in all groups, higher-use zones consist of

572 locations closer to large trees. Thus, season, forest type, and forest fragmentation all have effects

573 on lemur space use and ranging behavior.

575 Using Dynamic Brownian Bridge Movement Models, home range sizes of golden-crowned

576 sifaka groups varied between 3-32 hectares, indicating an incredible amount of home range size

577 variation within the species. These home range sizes are smaller than those of diademed sifaka

578 (Propithecus diadema), a species inhabiting Madagascar's eastern humid forests, which range

579 from 19-79 ha (95\% kernel; Irwin, 2008), but larger than those of Verreaux's sifaka (Propithecus

580 verreauxi), a species inhabiting Madagascar's southern dry forests, which have home range sizes

581 ranging from 5-10 ha [78]. Similar to this trend, mouse lemurs (Microcebus spp) inhabiting

582 western dry forests were able to maintain higher population densities than mouse lemur species 
583 inhabiting eastern humid forests [79]. Contrary to these previous findings and our predictions,

584 we found that golden-crowned sifaka groups in humid forest fragments do not occupy

585 significantly larger home range or core area sizes compared to groups living in moderate

586 evergreen or dry deciduous forest fragments. This finding was unexpected because Malagasy

587 humid evergreen forests are often described as being lower quality habitats compared to drier

588 forests due to decreased food availability, requiring wildlife to occupy larger ranges to meet

589 nutritional demands [80]. In sum, our study is the first determining that the same species of

590 sifaka can inhabit drastically different forest types and display great variation in home range size.

591

592 Our prediction that lemur home range sizes would vary between the rainy season and the dry

593 season was partially supported. While home range sizes (95\% isopleth) were not significantly

594 different between seasons, core area range size (50\% isopleth) was statistically larger for lemur

595 groups in the rainy season compared to the same groups' core area range sizes in the dry season.

596 Similar to findings of Milne-Edwards' sifaka, we found that golden-crowned sifaka maintained

597 similar home range (95\% isopleth) locations in both seasons, but displayed considerable seasonal

598 shifts in core area (50\% isopleth) locations [42]. This result demonstrates that golden-crowned

599 sifaka have significant site fidelity for their home ranges, but a lower degree of fidelity for core

600 area ranges. This difference is likely due to the non-uniform and seasonal variation in

601 distribution of resources which influenced how golden-crowned sifaka distributed their space use

602 to efficiently forage [81]. Surprisingly, the degree of core area overlap observed did not vary

603 based on the forest type or forest fragmentation level occupied.

604 
605 Unlike our prediction that sifaka groups in more degraded habitats would occupy larger home

606 ranges, we found limited evidence that forest fragmentation (edge vs. interior) influenced home

607 range or core area size in golden-crowned sifaka. Previous studies have demonstrated varying

608 effects of disturbance on home range size of eastern sifaka species in rainforest habitats. For

609 instance, diademed sifaka (Propithecus diadema) living in edge forests occupied significantly

610 smaller home range sizes than conspecifics in contiguous forests [41] while Milne-Edwards'

611 sifaka (Propithecus edwardsi) in fragmented (logged) forests maintained larger home range sizes

612 [42]. While these studies indicate contrasting effects of forest fragmentation on lemur home

613 range size, fragmentation and other anthropogenic habitat changes are known to produce

614 negative impacts on lemurs [82]. Unfortunately, the majority of lemur studies (87\%) examining

615 the influence of anthropogenic habitat changes on lemur health, genetics, biodiversity, and

616 behavior were conducted in the humid forests of eastern Madagascar [82]. Further, lemur

617 responses to habitat edges in dry forest are often highly variable, with groups avoiding, selecting,

618 or demonstrating no response in regards to feeding along forest edges. As a result, further

619 investigation of home ranges of golden-crowned sifaka and other dry forest lemurs are needed to

620 understand how increasing anthropogenic changes are influencing lemur ecology and

621 conservation.

622

623 Across seasons, regardless of forest type or forest fragmentation, golden-crowned sifaka groups

624 daily movement rates shifted, with groups moving farther per unit time in the rainy season.

625 Contrary to this finding in golden-crowned sifaka, previous studies indicate that Milne-Edward's

626 sifaka do not increase or decrease their distance moved per day (i.e., daily path length) between

627 seasons [42]. Thus, there exists some degree of variability among sifaka species. Movement rates 
628 in golden-crowned sifaka groups were also closely linked to home range size in that as home

629 range increased in the rainy season, so did the average distance moved per hour. This finding is

630 consistent elsewhere in highly mobile mammals as movement rates and resource availability

631 determined home range size of white-tailed deer (Odocoileus virginianus) and Iberian ibex

632 (Capra pyrenaica) $[83,84]$.

633

634 Aligning with our predictions, sifaka habitat selection was influenced by proximity to human

635 settlements and permanent manmade structures, with golden-crowned sifaka groups

636 preferentially avoiding these areas. Studies examining the influence of road networks on other

637 mammalian species have similarly found that elk (Cervus canadensis) and caribou (Rangifer

638 tarandus) tend to avoid road crossings and seek cover when in close proximity to road networks

639 [85]. Road expansion and paving is known to increase the prevalence of vehicle collisions with

640 wildlife (e.g., Asiatic cheetah (Acinonyx jubatus venaticus; Mohammadi et al., 2018) and Florida

641 panther (Puma concolor coryi; Criffield et al., 2018). The national road that bisects the global

642 range of golden-crowned sifaka is currently being improved to enhance access to mineral

643 reserves and transportation through the region. The combination of road expansion and human

644 population growth is expected to intensify the already harmful degree of resource extraction

645 within the region (e.g., selective logging of hardwoods and gold mining) [39]. Thus, given the

646 current level of avoidance golden-crowned sifaka display towards roads, the continued road

647 paving initiatives within their global range, and evidence gained from other mammalian studies,

648 increased avoidance on golden-crowned sifaka are likely. Our results indicating sifaka avoidance

649 of human villages have been documented in other mammalian taxa; for example, caracal

650 (Caracal caracal) avoided areas visited by and adjacent to human settlements [88]. Lastly, even 
651 low vehicle traffic (0-30 vehicles/12hrs) can lead to animal avoidance as demonstrated in

652 wolverines (Gulo gulo), where space use in regard to road networks led to avoidance and altered

653 movement patterns [89]. Consequently, increasing human activity and road prevalence has the

654 potential to impact foraging and space use behavior of wildlife species, and in the case of

655 golden-crowned sifaka, could result in an impact large enough to threaten their population.

657 Conclusions

659 Conservation implications

661 Our study illustrates the complex anthropogenic and ecological processes that influence 662 movement behavior of golden-crowned sifaka groups. We found clear evidence that human

663 settlements and road networks play an important role in shaping golden-crowned sifaka foraging 664 and ranging behavior. Additionally, ecological factors such as season are drivers of home range 665 size and space use in this species. In terms of conservation implications, our study illustrates the 666 importance of studying primate groups in both the rainy and dry seasons to gain an accurate 667 snapshot of their ecology and resources needs. More specifically, by understanding how forest 668 type influences golden-crowned sifaka movement and foraging behavior, we can make 669 conservation management plans specific to the individual forest types throughout the Loky-

670 Manambato Protected Area (humid, moderate evergreen, dry deciduous, littoral, etc.), rather than

671 the region as a whole. Our findings will also inform Malagasy infrastructure and road

672 development plans by working with local conservation NGOs, government officials, and

673 construction teams to limit construction nearby lemur home ranges that are most impacted by 
674 human activity. We would advise that the national road not be re-routed towards Binara, the

675 humid forest fragment, due to the strong avoidance lemurs display towards existing road

676 networks and the increased movement of lemurs within this forest fragment. We detected the

677 least avoidance of anthropogenic activity for lemurs in the moderate evergreen forest type,

678 suggesting they are more resilient to the negative effects of human infrastructure. Overall, as

679 anthropogenic disturbance continues to alter habitat structure throughout Madagascar, a deeper

680 knowledge of how fragmentation, habitat loss, and infrastructure development influence golden-

681 crowned sifaka space use, density, and population health will be essential for wildlife managers

682 to make well informed decisions that improve conservation plans for at-risk species.

\section{Acknowledgments}

685 We would like to sincerely thank Amidou Souleimany, Aylett Lipford, Giovanni Walters, our 686 local guides (Amadou, Andre, Augiste, Bezily, Christone, Da, Edward, Ishmael, Jaojoby, John, 687 Justin, Lahimena, Laurent, Lucien, Mamoud, Michelle, Moratombo, Patrice, Pierre, Seraphin, 688 Sylvano, Theodore, Thierry, Zoky), cooking staff (Ayati, Fatomia, Francia, Jao Fera, Nicole), 689 and porters, Fanamby (Serge Rajaobelina, Celin, Narcisse, Tiana Andriamanana, Sylvano

690 Tsialazo), and Madagascar Institute for the Conservation of Tropical Environments (MICET;

691 Benjamin Andriamihaja, Benji Randrianambinina, Claude, Nary) for their assistance with data 692 collection and logistics.

693

\section{Authors Contributions}


695 MS and IM designed the study. MS, BS, and TR conducted the fieldwork. MS, HA, and MC

696 conducted the coding and data analyses. MS wrote the first draft of the manuscript and all

697 authors contributed substantially to revisions.

$699 \quad$ Funding

700 We acknowledge funding from the Rufford Foundation and the National Science Foundation

701 GRFP (DGE 1651272). Opinions, findings, conclusions, or recommendations expressed are

702 those of the authors and do not necessarily reflect the views of the NSF.

703

704 Availability of data and materials

705 The datasets used and/or analyzed during the current study are available from the corresponding

706 author on reasonable request.

707

708 Declarations

709 Ethics approval and consent to participate

710 This research was conducted with permission from the Ministry of Foreign Affairs of

711 Madagascar, Madagascar National Parks, the Ministry of the Environment, Forests, and Tourism

712 (MEFT), and Madagascar Institute for the Conservation of Tropical Environments (MICET). 
713 MICET was also instrumental in permit acquisition (N015/19/MEEF/SG/DGF/DSAP/SCB) and

714 overall research coordination. Our animal follow methods were approved by the Virginia Tech

715 Institutional Animal Care and Use Committee (IACUC) office (permit \#17-127).

716

717 Consent for publication

718 Not applicable.

719

720 Competing interests

721 The authors declare that they have no competing interests.

\section{References}

724

725 1. Tabarelli M, Venceslau A, Cezar M, Paul J, Peres CA. Prospects for biodiversity conservation

726 in the Atlantic Forest : Lessons from aging human-modified landscapes. Biol Conserv.

$727 \quad 2010 ; 143: 2328-40$.

728 2. Allen AM, Singh NJ. Linking Movement Ecology with Wildlife Management and

729 Conservation. Front Ecol Evol. 2016;3:1-13.

730 3. Delciellos AC, Ribeiro SE, Vieira M V. Habitat fragmentation effects on fine-scale

731 movements and space use of an opossum in the Atlantic Forest. J Mammal. 2017;98:1129-36.

732 4. Gastón A, Ciudad C, Mateo-Sánchez MC, García-Viñas JI, López-Leiva C, Fernández-Landa 
733 A, et al. Species' habitat use inferred from environmental variables at multiple scales: How much

734 we gain from high-resolution vegetation data? Int J Appl Earth Obs Geoinf. 2017;55:1-8.

735 5. Festa-Bianchet M, Apollonio M. Animal Behavior and Wildlife Conservation. Washington,

736 DC: Island Press; 2003.

737 6. Merrick MJ, Koprowski JL. Should we consider individual behavior differences in applied 738 wildlife conservation studies? Biol Conserv [Internet]. Elsevier Ltd; 2017;209:34-44. Available

739 from: http://dx.doi.org/10.1016/j.biocon.2017.01.021

740 7. Grüss A, Kaplan DM, Guénette S, Roberts CM, Botsford LW. Consequences of adult and 741 juvenile movement for marine protected areas. Biol Conserv. 2011;144:692-702.

742 8. Angeloni L, Schlaepfer MA, Lawler JJ, Crooks KR. A reassessment of the interface between

743 conservation and behaviour. Anim Behav. 2008;75:731-7.

744 9. Choi CY, Peng HB, He P, Ren XT, Zhang S, Jackson M V., et al. Where to draw the line?

745 Using movement data to inform protected area design and conserve mobile species. Biol Conserv 746 [Internet]. Elsevier; 2019;234:64-71. Available from:

747 https://doi.org/10.1016/j.biocon.2019.03.025

748 10. Berger-Tal O, Polak T, Oron A, Lubin Y, Kotler BP, Saltz D. Integrating animal behavior 749 and conservation biology: A conceptual framework. Behav Ecol. 2011;22:236-9.

750 11. Cooke SJ, Blumstein DT, Buchholz R, Caro T, Fernández-Juricic E, Franklin CE, et al. 751 Physiology, behavior, and conservation. Physiol Biochem Zool. 2014;87:1-14.

752 12. Anthony LL, Blumstein DT. Integrating behaviour into wildlife conservation: The multiple 753 ways that behaviour can reduce N(e). Biol Conserv. 2000;95:303-15.

754 13. Berger-Tal O, Blumstein DT, Carroll S, Fisher RN, Mesnick SL, Owen MA, et al. A 755 systematic survey of the integration of animal behavior into conservation. Conserv Biol. 
757 14. Shillinger GL, Palacios DM, Bailey H, Bograd SJ, Swithenbank AM, Gaspar P, et al.

758 Persistent leatherback turtle migrations present opportunities for conservation. PLoS Biol.

$759 \quad 2008 ; 6: 1408-16$.

760 15. Reyna-hurtado R, Teichroeb JA, Bonnell TR, Hernández-sarabia RU, Vickers SM, Serio-

761 silva JC, et al. Primates adjust movement strategies due to changing food availability. Behav

762 Ecol. 2018;29:368-76.

763 16. Trapanese C, Meunier H, Masi S. What, where and when: spatial foraging decisions in 764 primates. Biol. Rev. 2019. p. 483-502.

765 17. Rosenzweig ML. A Theory of Habitat Selection. Ecology [Internet]. 1981;62:327-35.

766 Available from: http://www.jstor.org/stable/1936707?seq=1\#page_scan_tab_contents

767 18. Nagy-Reis MB, Setz EZF. Foraging strategies of black-fronted titi monkeys (Callicebus

768 nigrifrons) in relation to food availability in a seasonal tropical forest. Primates. Springer Japan; $769 \quad 2017 ; 58: 149-58$.

770 19. Campera M, Serra V, Balestri M, Barresi M, Ravaolahy M, Randriatafika F, et al. Effects of 771 Habitat Quality and Seasonality on Ranging Patterns of Collared Brown Lemur (Eulemur 772 collaris) in Littoral Forest Fragments. Int J Primatol. 2014;35:957-75.

773 20. Pope NS, Jha S. Seasonal food scarcity prompts long-distance foraging by a wild social bee. 774 Am Nat. 2018;191:45-57.

775 21. Wato YA, Prins HHT, Heitkönig IMA, Wahungu GM, Ngene SM, Njumbi S, et al.

776 Movement patterns of African Elephants (Loxodonta africana) in a Semi-arid Savanna suggest

777 that they have information on the location of dispersed water sources. Front Ecol Evol.

$778 \quad 2018 ; 6: 1-8$. 
22. Asensio N, Schaffner CM, Aureli F. Variability in core areas of spider monkeys (Ateles geoffroyi) in a tropical dry forest in Costa Rica. Primates. 2012;53:147-56.

23. Branco PS, Merkle JA, Pringle RM, Pansu J, Potter AB, Reynolds A, et al. Determinants of

782 elephant foraging behaviour in a coupled human-natural system: Is brown the new green? J

783 Anim Ecol. 2019;88:780-92.

784 24. Rice MB, Apa AD, Wiechman LA. The importance of seasonal resource selection when

785 managing a threatened species: Targeting conservation actions within critical habitat

786 designations for the Gunnison sage-grouse. Wildl Res. 2017;44:407-17.

787 25. Street GM, Fieberg J, Rodgers AR, Carstensen M, Moen R, Moore SA, et al. Habitat

788 functional response mitigates reduced foraging opportunity : implications for animal fitness and

789 space use. Landsc Ecol. Springer Netherlands; 2016;31:1939-53.

790 26. Said S, Servanty S. The influence of landscape structure on female roe deer home-range size.

791 Landsc Ecol. 2005;20:1003-12.

792 27. Holzman S, Conroy MJ, Pickering J. Home Range, Movements, and Habitat Use of Coyotes

793 in Southcentral Georgia. J Wildl Manage. 1992;56:139-46.

794 28. McLean KA, Trainor AM, Asner GP, Crofoot MC, Hopkins ME, Campbell CJ, et al.

795 Movement patterns of three arboreal primates in a Neotropical moist forest explained by LiDAR-

796 estimated canopy structure. Landsc Ecol. Springer Netherlands; 2016;31:1849-62.

797 29. Campos FA, Bergstrom ML, Childers A, Hogan JD, Jack KM, Melin AD, et al. Drivers of

798 home range characteristics across spatiotemporal scales in a Neotropical primate, Cebus

799 capucinus. Anim Behav. Elsevier Ltd; 2014;91:93-109.

800 30. Haddad NM, Brudvig LA, Clobert J, Davies KF, Gonzalez A, Holt RD, et al. Habitat

801 fragmentation and its lasting impact on Earth 's ecosystems. Sci Adv. 2015;1-10. 
802 31. Menchaca A, Rossi NA, Froidevaux J, Dias-freedman I, Caragiulo A, Wultsch C, et al.

803 Population genetic structure and habitat connectivity for jaguar (Panthera onca) conservation in

804 Central Belize. BMC Genet. BMC Genetics; 2019;20:1-13.

805 32. Peaden JM, Nowakowski AJ, Tuberville TD, Buhlmann KA, Todd BD. Effects of roads and

806 roadside fencing on movements, space use, and carapace temperatures of a threatened tortoise.

807 Biol Conserv. Elsevier; 2017;214:13-22.

808 33. Rogan MS, Miller JRB, Lindsey PA, Mcnutt JW. Socioeconomic drivers of illegal bushmeat

809 hunting in a Southern African Savanna. Biol Conserv. Elsevier; 2018;226:24-31.

810 34. Cardillo M, MacE GM, Gittleman JL, Jones KE, Bielby J, Purvis A. The predictability of

811 extinction: Biological and external correlates of decline in mammals. Proc R Soc B Biol Sci.

$812 \quad 2008 ; 275: 1441-8$.

813 35. Zeller KA, Wattles DW, Conlee L, Destefano S. Black bears alter movements in response to

814 anthropogenic features with time of day and season. Mov Ecol. Movement Ecology; 2019;7:1-

81514.

816 36. Polfus JL, Hebblewhite M, Heinemeyer K. Identifying indirect habitat loss and avoidance of

817 human infrastructure by northern mountain woodland caribou. Biol Conserv [Internet]. Elsevier

818 Ltd; 2011;144:2637-46. Available from: http://dx.doi.org/10.1016/j.biocon.2011.07.023

819 37. Isaac NJB, Cowlishaw G. How species respond to multiple extinction threats. Proc R Soc B

820 Biol Sci. 2004;271:1135-41.

821 38. Almeida-Rocha JM d., Peres CA, Oliveira LC. Primate responses to anthropogenic habitat

822 disturbance: A pantropical meta-analysis. Biol Conserv [Internet]. Elsevier; 2017;215:30-8.

823 Available from: http://dx.doi.org/10.1016/j.biocon.2017.08.018

824 39. Estrada A, Garber PA, Rylands AB, Roos C, Fernandez-duque E, Fiore A Di, et al. 
825 Impending extinction crisis of the world's primates: Why primates matter. Sci Adv. 2017;3:182616.

827 40. Vieilledent G, Grinand C, Rakotomalala FA, Ranaivosoa R, Rakotoarijaona J, Allnutt TF, et

828 al. Combining global tree cover loss data with historical national forest cover maps to look at six 829 decades of deforestation and forest fragmentation in Madagascar. Biol Conserv. Elsevier; $830 \quad 2018 ; 222: 189-97$.

831 41. Irwin MT. Feeding ecology of Propithecus diadema in forest fragments and continuous

832 forest. Int J Primatol. 2008;29:95-115.

833 42. Gerber BD, Arrigo-Nelson S, Karpanty SM, Kotschwar M, Wright PC. Spatial Ecology of

834 the Endangered Milne-Edwards' Sifaka (Propithecus edwardsi): Do Logging and Season Affect

835 Home Range and Daily Ranging Patterns? Int J Primatol. 2012;33:305-21.

836 43. Erhart EM, Tecot SR, Grassi C. Interannual Variation in Diet, Dietary Diversity, and Dietary

837 Overlap in Three Sympatric Strepsirrhine Species in Southeastern Madagascar. Int J Primatol.

838 International Journal of Primatology; 2018;39:289-311.

839 44. Herrera JP, Borgerson C, Tongasoa L, Andriamahazoarivosoa P, Rasolofoniaina BJR,

840 Rakotondrafarasata ER, et al. Estimating the population size of lemurs based on their mutualistic

841 food trees. J Biogeogr. 2018;1-18.

842 45. Baden AL. A description of nesting behaviors, including factors impacting nest site selection 843 , in black-and-white ruffed lemurs (Varecia variegata). Ecol Evol. 2019;9:1010-28.

844 46. Lahann P, Dausmann KH. Live fast, die young: flexibility of life history traits in the fat845 tailed dwarf lemur (Cheirogaleus medius ). Behav Ecol Sociobiol. 2011;65:381-90.

846 47. Norscia I, Carrai V, Borgognini-Tarli SM. Influence of Dry Season and Food Quality and 847 Quantity on Behavior and Feeding Strategy of Propithecus verreauxi in Kirindy, Madagascar. Int 
J Primatol. 2006;27:1001-22.

849 48. Quéméré E, Champeau J, Besolo A, Rasolondraibe E, Rabarivola C, Crouau-Roy B, et al.

850 Spatial variation in density and total size estimates in fragmented primate populations: The

851 golden-crowned sifaka (Propithecus tattersalli). Am J Primatol. 2010;72:72-80.

852 49. Quéméré E, Crouau-Roy B, Rabarivola C, Louis EE, Chikhi L. Landscape genetics of an

853 endangered lemur (Propithecus tattersalli) within its entire fragmented range. Mol Ecol.

$854 \quad 2010 ; 19: 1606-21$.

855 50. Goodman SM, Raherilalao MJ, Wohlhauser S. Site 6: Loky Manambato. Terr Prot Areas

856 Madagascar Their Hist Descr Biot. 2018.

857 51. Quemere E, Amelot X, Pierson J, Crouau-Roy B, Chikhi L. Genetic data suggest a natural

858 prehuman origin of open habitats in northern Madagascar and question the deforestation

859 narrative in this region. Proc Natl Acad Sci [Internet]. 2012;109:13028-33. Available from:

860 http://www.pnas.org/cgi/doi/10.1073/pnas.1200153109

861 52. Salmona J, Heller R, Quéméré E, Chikhi L. Climate change and human colonization

862 triggered habitat loss and fragmentation in Madagascar. Mol Ecol. 2017;26:5203-22.

863 53. Lehmann J, Boesch C. Social influences on ranging patterns among chimpanzees (Pan

864 troglodytes verus) in the Ta1 National Park, Cote d' Ivoire. Behav Ecol. 2002;14:642-9.

865 54. Steiniger S, Hunter AJS. A scaled line-based kernel density estimator for the retrieval of 866 utilization distributions and home ranges from GPS movement tracks. Ecol Inform. 2013;13:1-8.

867 55. Avgar T, Potts JR, Lewis MA, Boyce MS. Integrated step selection analysis : bridging the 868 gap between resource selection and animal movement. Methods Ecol Evol. 2016;7:619-30.

869 56. Kranstauber B. Modelling animal movement as Brownian bridges with covariates. Mov Ecol.

870 Movement Ecology; 2019;7:1-10. 
871 57. Fieberg J, Borger L. Could you please phrase “" home range "” as a question? J Mammal.

$872 \quad 2012 ; 93: 890-902$.

873 58. Kranstauber B, Kays R, Lapoint SD, Wikelski M, Safi K. A dynamic Brownian bridge

874 movement model to estimate utilization distributions for heterogeneous animal movement. J

875 Anim Ecol. 2012;81:738-46.

876 59. Meyers DM. The Effects of Resource Seasonality on Behavior and Reproduction in the

877 Golden-crowned Sifaka (Propithecus Tattersalli, Simons, 1988) in Three Malagasy Forests.

878 Duke University; 1993.

879 60. Erkert HG, Kappeler PM. Arrived in the light: diel and seasonal activity patterns in wild

880 Verreaux s sifakas ( Propithecus v . verreauxi; Primates : Indriidae ). Behav Ecol Sociobiol.

$881 \quad 2004 ; 57: 174-86$.

882 61. Altmann J. Observational Study of Behavior: Sampling Methods. Behaviour. 1974;49:227-

88367.

884 62. Gurarie E, Andrews RD, Laidre KL. A novel method for identifying behavioural changes in 885 animal movement data. Ecol Lett. 2009;12:395-408.

886 63. Horne JS, Garton EO, Krone SM, Lewis JS. Analyzing animal movements using Brownian 887 bridges. Ecology. 2007;88:2354-63.

888 64. Kranstauber B, Smolla M, Scharf A. Visualizing and Analyzing Animal Track Data. 2013.

889 65. R Core Team. Vienna, Austria: R Foundation for Statistical Computing; 2020.

890 66. Burnham KP, Anderson DR. Model selection and multimodel inference: a practical

891 information-theoretic approach. New York, New York: Springer-Verlag; 2002.

892 67. Atwood TC, Weeks HP. Spatial home-range overlap and temporal interaction in eastern

893 coyotes: The influence of pair types and fragmentation. Can J Zool. 2003;81:1589-97. 
894 68. Bates D, Mächler M, Bolker BM, Walker SC. Fitting Linear Mixed-Effects Models Using 895 1me4. J Stat Softw. 2015;67:1-48.

896 69. Hurvich CM, Tsai CL. Regression and time series model selection in small samples.

897 Biometrika. 1989;76:297-307.

898 70. Lele SR, Merrill EH, Keim J, Boyce MS. Selection, use, choice and occupancy: clarifying 899 concepts in resource selection studies. J Anim Ecol. 2013;82:1183-91.

900 71. Manly BF, McDonald L, Thomas D, McDonald TL, Erickson WP. Resource Selection by 901 Animals. 2nd ed. Springer Netherlands; 2002.

902 72. Johnson DJ. The comparison of usage and availability measurements for evaluating resource 903 preference. Ecology. 1980;61:65-71.

904 73. Benson JF. Improving rigour and efficiency of use-availability habitat selection analyses with 905 systematic estimation of availability. Methods Ecol Evol. 2013;4:244-51.

906 74. Gillies CS, Hebblewhite M, Nielsen SE, Krawchuk MEGA, Aldridge CL, Jacqueline L, et al. 907 Application of random effects to the study of resource. J Anim Ecol. 2006;75:887-98.

908 75. Hebblewhite M, Merrill E. Modelling wildlife - human relationships for social species with 909 mixed-effects resource selection models. J Appl Ecol. 2008;45:834-44.

910 76. Pebesma E, Graeler B, Pebesma ME. Package 'gstat'. 2019.

911 77. De Smith MJ, Goodchild MF, Longley PA. Geospatial Analysis: A Comprehensive Guide to 912 Principles Techniques and Software Tools. 6th ed. Ingram Publisher Services; 2018.

913 78. Benadi G, Fitchel C, Kappeler P. Intergroup Relations and Home Range Use in Verreaux's

914 Sifaka (Propithecus verreauxi ). Am J Primatol. 2008;70:956-65.

915 79. Setash CM, Zohdy S, Gerber BD, Karanewsky CJ. A biogeographical perspective on the 916 variation in mouse lemur density throughout Madagascar. Mamm Rev. 2017;47:212-29. 
917 80. Wright PC. Lemur traits and Madagascar ecology: coping with an island environment. Am J

918 Phys Anthropol [Internet]. 1999;Suppl 29:31-72. Available from:

919 http://eutils.ncbi.nlm.nih.gov/entrez/eutils/elink.fcgi?dbfrom=pubmed\&id=10601983\&retmode=

920 ref\&cmd=prlinks\%5Cnpapers2://publication/uuid/E29CB817-D796-49CD-81E0-

$921 \quad 0405 \mathrm{~F} 2237 \mathrm{~A} 27$

922 81. Ostro LET, Silver SC, Koontz FW, Young TP. Ranging behavior of translocated and

923 established groups of black howler Ranging behavior of translocated and established groups of

924 black howler monkeys Alouatta pigra in Belize, Central America. Biol Conserv. 1999;87:181-

92590.

926 82. Kling KJ, Yaeger K, Wright PC. Trends in forest fragment research in Madagascar:

927 Documented responses by lemurs and other taxa. Am J Primatol. 2020;1-14.

928 83. Rhoads CL, Bowman JL, Eyler B. Home Range and Movement Rates of Female Exurban

929 White-Tailed Deer. J Wildl Manage. 2010;74:987-94.

930 84. Viana DS, Granados JE, Fandos P, Pérez JM, Cano-manuel FJ, Burón D, et al. Linking

931 seasonal home range size with habitat selection and movement in a mountain ungulate. Mov

932 Ecol. Movement Ecology; 2018;6:1-11.

933 85. Prokopenko CM, Boyce MS, Avgar T. Characterizing wildlife behavioural responses to

934 roads using integrated step selection analysis. J Appl Ecol. 2017;54:470-9.

935 86. Mohammadi A, Almasieh K, Clevenger AP, Fatemizadeh F. Road expansion: A challenge to 936 conservation of mammals, with particular emphasis on the endangered Asiatic cheetah in Iran. J

937 Nat Conserv. Elsevier; 2018;43:8-18.

938 87. Criffield M, Van De Kerk M, Leone E, Cunningham MW, Lotz M, Oli MK, et al. Assessing 939 impacts of intrinsic and extrinsic factors on Florida panther movements. J Mammal. 
$940 \quad 2018 ; 99: 702-12$.

941 88. Ünal Y, Pekin BK, Oğurlu I, Süel H, Koca A. Human, domestic animal, Caracal (Caracal

942 caracal), and other wildlife species interactions in a Mediterranean forest landscape. Eur J Wildl

943 Res. 2020;66:1-10.

944 89. Scrafford MA, Avgar T, Heeres R, Boyce MS. Roads elicit negative movement and habitat-

945 selection responses by wolverines (Gulo gulo luscus). Behav Ecol. 2018;29:534-42.

946 